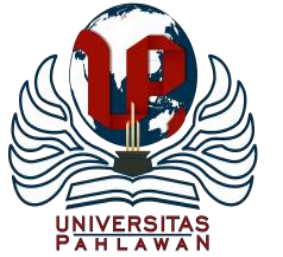

Jurnal Abdidas Volume 1Nomor 1 Tahun 2020 Halaman 1-6

JURNAL ABDIDAS

Community Development Service on Educational and Health Sciences https://journal.universitaspahlawan.ac.id/index.php/abdidas/index

\title{
Pelatihan Pembelajaran E-Learning Berbasis Edmodo Bagi Guru Sekolah Dasar
}

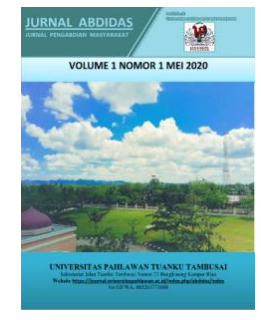

\section{Fadhilaturrahmi $^{1}$}

Universitas Pahlawan Tuanku Tambusai, Riau, Indonesia ${ }^{1}$

e-mail : fadhilaturrahmi@universitaspahlawan.ac.id ${ }^{1}$

\begin{abstract}
Abstrak
Program Kemitraan Masyarakat (PKM) ini dilaksanakan di SDN 003 dan SDN 016. Pelatihan ini didasari kurangnya pengetahuan guru terahadap pemanfaatan handphone android yang dapat digunakan dalam proses pembelajaran, karena yang selama ini handphone android hanya dimanfaatkan untuk sosial media; Pelatihan tentang pembelajaran E-Learning tidak pernah didapatkan oleh guru, Proses pembelajaran yang dilakukan guru telah menggunakan pembelajaran berbasis computer based learning dengan memanfaatkan infocus tanpa terhubung dengan internet; Keinginan sekolah/guru untuk meningkatkan kualitas sumber daya manusia sangat tinggi, namun terkendala oleh banyak faktor seperti pendanaan, jangkauan teknologi, fasilitas sekolah, kesempatan mengikuti pelatihan dan lain-lain. Salah satu solusi yang direkomendasikan oleh penulis adalah perlu diadakan kegiatan Pelatihan Pembelajaran E-Learning Berbasis Edmodo. Dengan adanya Program Kemitraan Masyarakat (PKM) ini diharapkan terjadi peningkatan penerapan IPTEK pada kedua sekolah tersebut, peningkatan kualitas pembelajaran serta meningkatkan keterampilan softskill dan hardskill. Metode yang digunakan untuk mencapai tujuan tersebut yakni mengoptimalkan kerja sama (perencanaan, pelaksanaan dan evaluasi program) dengan pihak mitra dengan harapan agar guru-guru dapat mengoptimalkan pembelajaran E-learning berbasis Edmodo.
\end{abstract}

Kata Kunci: Pembelajaran E-Learning, Edmodo, Guru sekolah dasar

\begin{abstract}
The Community Partnership Program (PKM) is implemented at SDN 003 dan SDN 016. This training is based on the lack of teacher's knowledge of the use of an android mobile phone that can be used in the learning process, because so far the android mobile phone is only used for social media; Training on E-Learning learning has never been obtained by the teacher. The learning process carried out by the teacher has used computer-based learning by utilizing infocus without being connected to the internet; The desire of schools / teachers to improve the quality of human resources is very high, but is constrained by many factors such as funding, technology outreach, school facilities, training opportunities and others. One of the solutions recommended by the author is to hold Edmodo-based E-Learning Learning Training. With the existence of the Community Partnership Program (PKM), it is expected that an increase in the application of science and technology in the two schools will improve the quality of learning and improve soft skills and hard skills. The method used to achieve these objectives is to optimize cooperation (program planning, implementation and evaluation) with partners in the hope that teachers can optimize Edmodo-based E-learning learning. .
\end{abstract}

Keywords: E-Learning , Edmodo, Elementary school teacher

@ Jurnal Abdidas 2020

$\triangle$ Corresponding author :

Address : Alamat penulis

Email : Email Penulis

Phone : Nomor HP:
ISSN xxxx-xxxx (Media Cetak)

ISSN $x x x x-x x x x$ (Media Online) 


\section{PENDAHULUAN}

Bangkinang, Ibukota dari kabupaten Kampar Riau yang berjarak $60 \mathrm{~km}$ dari Kota Pekanbaru. Di Bangkinang terdapat 19 Sekolah Dasar (SD), beberapa diantaranya adalah SDN 003 Bangkinang dan SDN 016 Bangkinang. Lokasi SDN 003 Bangkinang dan SDN 016 Bangkinang beralamat di J1 Mayor Ali Rasyid No 14 RT5 RW3 Kelurahan Bangkinang Kecamatan Bangkinang Kota. Kedua sekolah ini merupakan sekolah inti dari beberapa SD yang ada dikomplek sekolah tersebut. Kedua sekolah ini sangat diminati oleh para orangtua disekitar. Setiap kali dibuka penerimaan murid baru, sekolah tersebut selalu dibanjiri pendaftar, hal ini buktikan dengan adanya kelas satu terdiri dari dua rombel, selain karena letaknya yang strategis, sekolah ini pun mudah untuk alat transportasinya. Jumlah siswa yang terdapat di SDN 003 Bangkinang berjumlah 244 siswa dan jumlah siswa yang terdapat di SDN 016 Bangkinang berjumlah 178 siswa.

Kedua sekolah ini telah mendapatkan akreditasi A, namun berdasarkan hasil observasi, wawancara serta diskusi yang dilakukan pada bulan Mei 2017 diperoleh informasi bahwasanya dalam hal penerapan Iptek terutama yang berkaitan dengan pemanfaatan Internet dalam proses pembelajaran sangat minim sekali. Hal ini dikarenakan ada beberapa kendala yang menyebabkan penerapan Iptek tidak dapat dilakukan secara optimal diantaranya: 1. Kurang terampilnya guru dalam mengoperasikan komputer; 2. Kurangnya pengetahuan guru terhadap penggunaan aplikasi online yang dapat diterapkan dalam proses pembelajaran; 3 . Kurangnya pengetahuan guru terhadap pemanfaatan handphone android yang dapat digunakan dalam proses pembelajaran, karena yang selama ini handphone android hanya dimanfaatkan untuk sosial media; 4.Pelatihan tentang pembelajaran E-Learning tidak pernah didapatkan oleh guru, walaupun guru sudah termasuk guru yang profesional karena sudah tersertifikasi; 5. Proses pembelajaran yang dilakukan guru telah menggunakan pembelajaran berbasis computer based learning dengan memanfaatkan infocus tanpa terhubung dengan internet; 6. Keinginan sekolah/guru untuk meningkatkan kualitas sumber daya manusia sangat tinggi, namun terkendala oleh banyak faktor seperti pendanaan, jangkauan teknologi, fasilitas sekolah, kesempatan mengikuti pelatihan dan lainlain.

Berkaitan permasalahan yang telah dipaparkan di atas, maka pembelajaran yang dilakukan oleh guru selama ini kurang terlaksana dengan optimal dalam hal pemanfataan Iptek. Maka Kepala Sekolah dan Pelaksana PKM memandang perlu untuk melaksanakan kegiatan pengabdian masyarakat dengan melibatkan guru SDN 003 Bangkinang dan SDN 016 Bangkinang dalam hal pembelajaran E-Learning berbasis Edmodo ini. Karena pembelajaran pada hakikatnya tidak hanya sekedar menyampaikan pesan kepada siswa, tetapi pembelajaran merupakan aktifitas kompleks dan profesional yang menuntut guru agar dapat melakukan kegiatan pembelajaran dengan terampil dan terpadu. Hal ini memungkinkan siswa dapat belajar secara efektif dan efesien. Tiap usaha mengajar yang dilakukan oleh guru sebenarnya ingin menumbuhkan atau menyempurnakan pola perilaku tertentu dalam diri siswa

\section{METODE}

Berdasarkan permasalahan yang dihadapi oleh mitra, , maka solusi yang ditawarkan adalah sebagai berikut:

1. Menambah pengetahuan guru tentang pemanfaatan pembelajaran berbasis edmodo.

2. Menambah pengetahuan guru tentang perkembangan pembelajaran yang bersifat E-Learning atau IT. 
Desain Ipteks dalam kegiatan pengabdian adalah sebagai berikut:

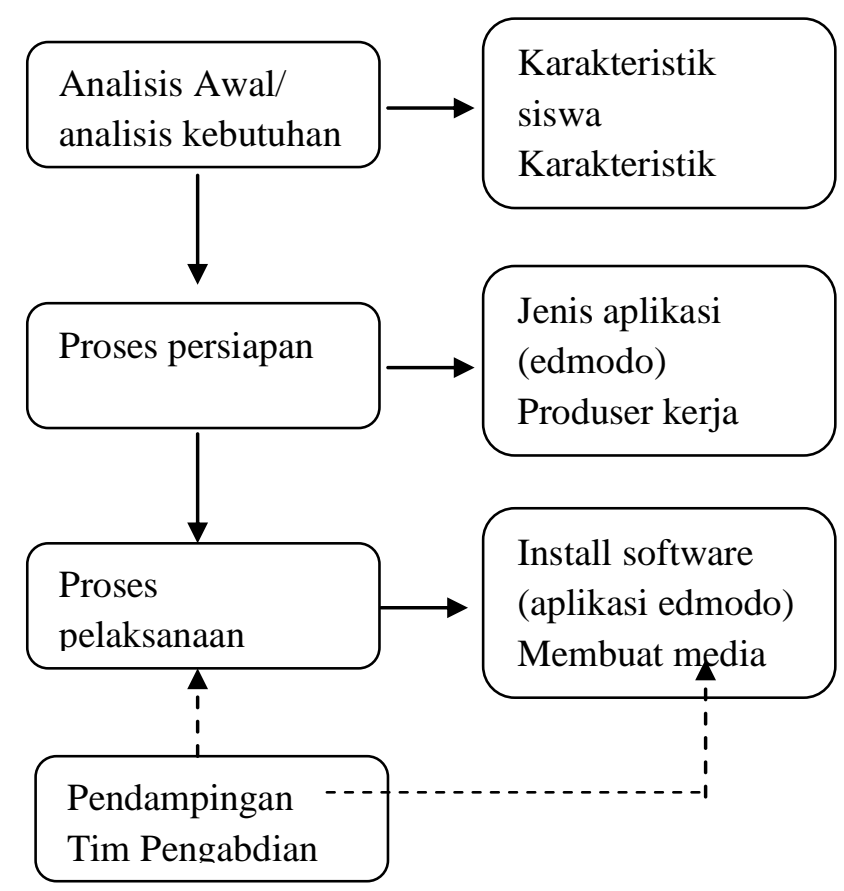

Gambar 2 Skema Kegiatan PKM

Mekanisme Pelaksanaan Kegiatan. Pelaksanaan kegiatan pengabdian ini mengikuti aktivitas pelaksanaan penelitian tindakan yang terdiri dari Persiapan, Pelaksanaan (tindakan), observasi dan Evaluasi dan refleksi.

a. Perencaaan

Kegiatan perencaan sebagai berikut:

1. Melakukan koordinasi dengan LPM Universitas Pahlawan Tuanku Tambusai dan Dinas Pendidikan dan Kebudayaan.

2. Sosialisasi Kegiatan Pengabdian kepada sekolah mitra dengan mengundang Dinas terkait, Kepala sekolah dan seluruh guru mitra.

3. Penyusunan program pengabdian berdasarkan hasil analisis situasi, analisis siswa, analisis materi dan analisis kebutuhan guru.

b. Pelaksanaan Tindakan

1. Pembentukan dan pendampingan kelompok guru;

2. Pelatihan tentang pembelajaran ELearning berbasis edmodo
3. Menambah pengetahuan guru tentang pembelajaran E-Learning berbasis edmodo.

4. Mendemonstrasikan penggunaan edmodo dalam proses pembelajaran;

c. Observasi dan Evaluasi

Kegiatan observasi dilakukan secara langsung oleh tim pelaksana. Observasi berupa hasil kerja peserta (guru mitra) terhadap pembelajaran E-Learning berbasis edmodo. Proses evaluasi dilaksanakan untuk mengetahui kekurangan dan kendala dalam pelaksanaan kegiatan pengabdian.

d. Refleksi

Refleksi dilakukan bersama antara tim dan peserta (guru mitra). Hal ini dilakukan untuk mengetahui seluruh proses pelaksanaan kegiatan.

\section{HASIL DAN PEMBAHASAN}

Terkait dengan permasalahan yang telah dipaparkan pada analisis situasi dan permasalahan mitra maka diperlukan sebuah solusi yang tepat. Salah satu alternatif solusi yang ditawarkan adalah dengan melakukan Pelatihan Pembelajaran ELearning Berbasis Edmodo bagi Guru SDN 003 dan SDN 016 Bangkinang Kabupaten Kampar.

Pembelajaran E-Learning adalah pendekatan pembelajaran melalui perangkat komputer dalam bentuk PC, Laptop, Netbook, Tablet dan HP yang berbasis android, yang tersambung dengan internet, dimana siswa berupaya memperoleh bahan belajar yang sesuai dengan kebutuhannya. E-learning dapat dipandang sebagai suatu sistem yang dikembangkan dalam upaya peningkatan kualitas pembelajaran dengan berupaya menembus keterbatasan ruang dan waktu (Darmawan, 2012).

Sistem E-learning merupakan suatu bentuk implementasi teknologi yang ditujukan untuk membantu proses kegiatan belajar mengajar 
yang dikemas dalam bentuk elektronik/digital dan pelaksanaannya membutuhkan sarana komputer berbasis web dalam situs internet. Pada dasarnya E-learning mengandung pengertian dan memberikan jangkauan proses belajar seperti biasanya. Aplikasi E-learning bisa digunakan sebagai salah satu fasilitas baik secara formal maupun informal untuk aktivitas pelatihan dan kegiatan belajar mengajar menggunakan intranet, CD-ROM, Video, DVD, televisi, handphone,PDA dan lainnya. Tetapi dalam hal pembelajaran $E$ learning yang diterapkan dalam proses pembelajaran adalah pembelajaran E-Learning berbasis Edmodo.

Edmodo adalah jejaring sosial dan layanan microblogging yang di desain khusus untuk dunia pendidikan, yang dapat dioperasikan seperti layaknya Twitter. Dengan membatasi jalan akses ke ruang khusus atau grup, guru dan siswa dapat saling mengirim catatan, link, berkas, pengumuman, tugas dan bertukar informasi di lingkungan yang aman (Wankel, 2011:24). Edmodo adalah jejaring sosial pribadi bagi guru dan siswa dengan platform sosial yang aman. Dengan model kicauan seperti situs jejaring sosial pada umumnya, Edmodo dapat menjadikan jaringan khusus bagi guru dan siswa untuk berbagi ide, berkas, peristiwa, dan tugas (Shelly, 2001:654). Edmodo adalah situs microblogging yang dapat digunakan di dalam kelas maupun rumah. Edmodo juga dapat membantu guru yang tidak bisa mengajar di kelas dengan memberikan materi pembelajaran secara online. Dalam Edmodo, Guru bisa memberikan tugas yang bisa ditentukan waktu pengumpulannya serta meng-upload materi pelajaran. Siswa juga bisa berbagi pemikiran atau ide lewat posting-nya di Edmodo atau jika disamakan dengan facebook, bisa dikatakan Update Status. Lebih tepatnya lagi, edmodo adalah "Facebook Guru dan Murid" karena fitur yang ditawarkan hampir sama dengan facebook. Seperti dalam pembelajaran tatap muka, Edmodo juga mendukung model pembelajaran "team teaching" . Guru dengan dapat mudah mengajak guru lain untuk menjadi co-teacher. Kode parent sama dengan kode yang diberikan kepada para siswa. Orang tua mempunyai hak akses untuk memantau perkembangan anak - anaknya dan bisa juga berdiskusi dengan guru.

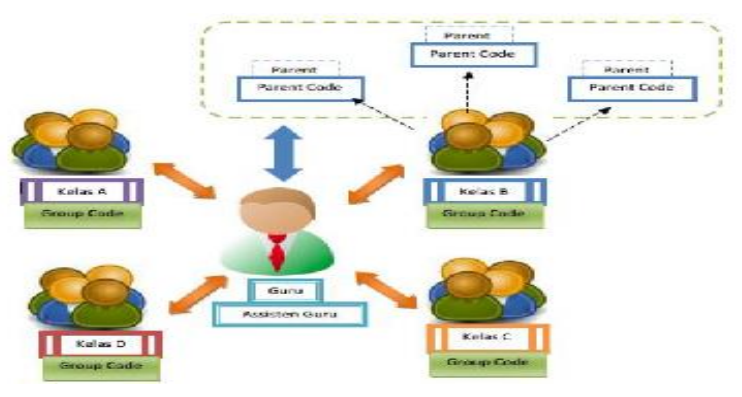

Gambar 1. Kolaborasi dalam Edmodo

Media pembelajaran edmodo bisa diakses melalui mobile dan sudah tersedia untuk smartphone Android dan iPhone. Semakin mudah untuk kalangan pendidikan untuk mempelajari dan semoga dengan adanya edmodo ini dapat menyama ratakan metode pembelajaran pendidikan di Indonesia. Situasi seperti ini juga bisa mengakibatkan kecemburuan sosial karea hanya kalangan menengah ke atas saja yang bisa mengaksesnya dengan gadget mereka, sementara kalangan bawah yang berada pada garis kemiskinan masih diangap belum mampu mempunyai gadget bisa terhalang untuk belajar. Tapi diperkirakan kondisi seperti ini bukan menjadi penghambat kegiatan belajar mengajar secara modern. Pada masa sekarang ini semua siswa tipe apapun akan cenderung menyenangi teknologi dan akrab dengannya. Hampir tidak ada siswa yang tidak punya akun di facebook, bahkan anak usia Sekolah Dasar pun banyak yang sudah punya.

Edmodo menggunakan desain yang hampir sama dengan Facebook, dan memberikan fasilitas kepada guru dan siswa tempat yang aman 
untuk saling berinteraksi, berkolaborasi dan berbagi konten informasi yang lain. Guru juga dapat mengoreksi, mengirim nilai, tugas dan kuis untuk siswa. Siswa dapat mengajukan pertanyaan dan meminta suatu tugas yang bisa dikerjakan sebagai pekerjaan rumah dan melihat nilai-nilai mereka serta menangapi apa bila guru telah memposting suatu tugas atau materi pelajaran. Guru juga dapat melakukan diskusi dengan topik yang telah diposting untuk diskusikan di kalangan siswa. Guru dapat membedakan dan individualize belajar melalui penciptaan sub-kelompok dalam kursus. Setelah setiap periode kursus selesai, guru menutup keluar jaringan dan menciptakan yang baru untuk kursus berikutnya. Edmodo juga memiliki iOS dan aplikasi Android tersedia melalui Apple App Store dan Google Putar (masing-masing) ini dibuat dan diterbitkan oleh pengembang Edmodo.

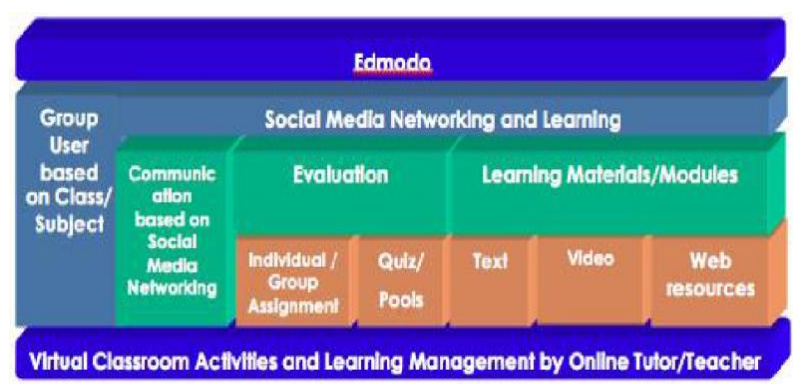

Gambar 2. Desain Diagram Media Sosial Edmodo

Dalam hal pembelajaran E-Learning berbasis Edmodo ini. Karena pembelajaran pada hakikatnya tidak hanya sekedar menyampaikan pesan kepada siswa, tetapi pembelajaran merupakan aktifitas kompleks dan profesional yang menuntut guru agar dapat melakukan kegiatan pembelajaran dengan terampil dan terpadu. Hal ini memungkinkan siswa dapat belajar secara efektif dan efesien. Tiap usaha mengajar yang dilakukan oleh guru sebenarnya ingin menumbuhkan atau menyempurnakan pola perilaku tertentu dalam diri siswa

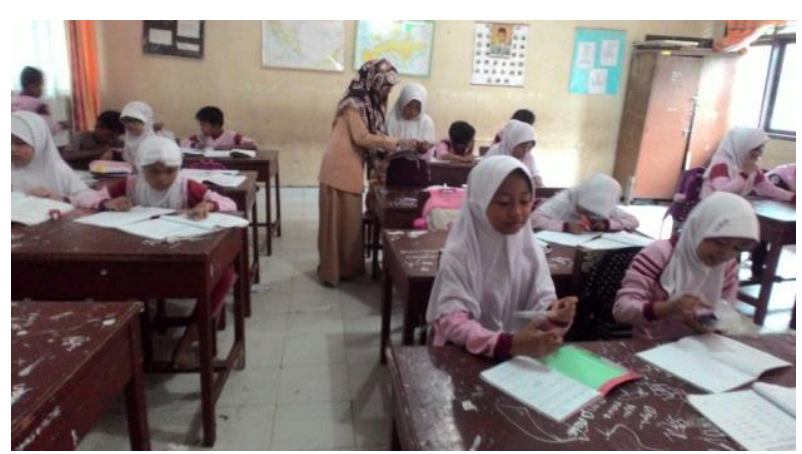

. Gambar 3 Proses Pembelajaran

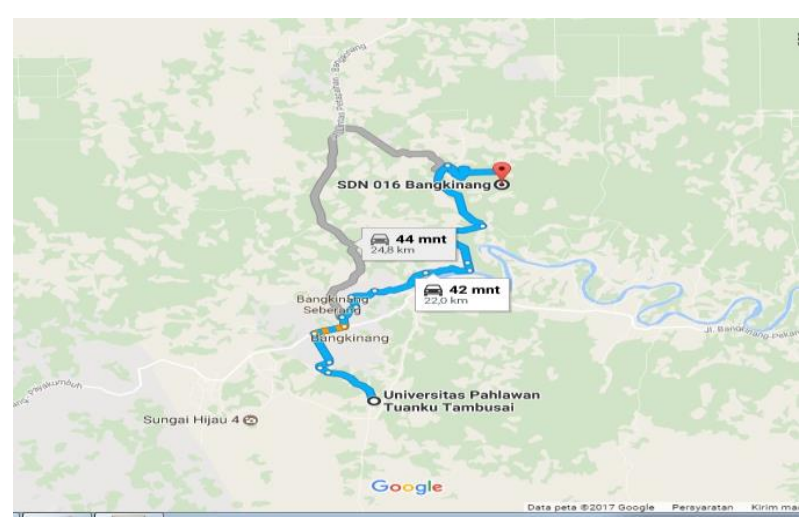

Gambar 4. Lokasi mitra

\section{SIMPULAN}

Program Kemitraan Masyarakat (PKM) ini dilaksanakan di SDN 003 dan SDN 016. Pelatihan ini didasari kurangnya pengetahuan guru terahadap pemanfaatan handphone android yang dapat digunakan dalam proses pembelajaran, karena yang selama ini handphone android hanya dimanfaatkan untuk sosial media; Pelatihan tentang pembelajaran E-Learning tidak pernah didapatkan oleh guru, Proses pembelajaran yang dilakukan guru telah menggunakan pembelajaran berbasis computer based learning dengan memanfaatkan infocus tanpa terhubung dengan internet; Keinginan sekolah/guru untuk meningkatkan kualitas sumber daya manusia sangat tinggi, namun terkendala oleh banyak faktor seperti pendanaan, jangkauan teknologi, fasilitas sekolah, kesempatan mengikuti pelatihan dan lainlain. Salah satu solusi yang direkomendasikan oleh penulis adalah perlu diadakan kegiatan Pelatihan Pembelajaran E-Learning Berbasis Edmodo. Dengan adanya Program Kemitraan Masyarakat (PKM) ini diharapkan terjadi peningkatan 
penerapan IPTEK pada kedua sekolah tersebut,

peningkatan kualitas pembelajaran serta meningkatkan keterampilan softskill dan hardskill. Metode yang digunakan untuk mencapai tujuan tersebut yakni mengoptimalkan kerja sama (perencanaan, pelaksanaan dan evaluasi program) dengan pihak mitra dengan harapan agar guru-guru dapat mengoptimalkan pembelajaran E-learning berbasis Edmodo. Dengan adanya pelatihan ini, sangat bermamfaat bagi guru untuk meningkatkan kemampuan penggunan IT dalam proses pembelaharan.

\section{DAFTAR PUSTAKA}

Darmawan, D. (2012). "Pendidikan Teknologi Informasi dan Komunikasi". Bandung. PT Remaja Rosdakarya

Shelly, G. B., \& Rosenblatt, H. J. (2012). Systems Analysis and Design. Boston: Cengage Learning. 